I Universidade Federal do Rio de Janeiro (UFRJ), Programa de Pós-Graduação em Sociologia e Antropologia (PPGSA), Rio de Janeiro, RJ, Brasil santosrodrigosp@gmail.com https://orcid.org/oooo-0003-3640-3365

I I Universidade Federal do Rio de Janeiro (UFRJ), Programa de Pós-Graduação em Sociologia e Antropologia (PPGSA), Rio de Janeiro, RJ, Brasil

\title{
CAPITALISMO, DEMOCRACIA E TEORIA SOCIAL EM KARL POLANYI: UMA ENTREVISTA COM GARETH DALE'
}

Nosso pensamento social, centrado que está na esfera econômica, está por isso mesmo mal equipado para lidar com as exigências econômicas desta era de ajustamento. Uma sociedade centrada no mercado como a nossa deve achar difícil, senão impossível, avaliar com justiça as limitações da importância do econômico. Pois, uma vez que as atividades cotidianas do homem foram organizadas por meio de mercados de vários tipos, motivados no lucro, determinados por atitudes competitivas e governados por uma escala de valor utilitário, sua sociedade se torna um organismo que é, em todos os aspectos essenciais, subserviente a propósitos lucrativos. Tendo absolutizado assim o motivo do lucro na prática, o ser humano perde a capacidade de relativizá-lo mentalmente outra vez. Sua imaginação é cercada por limites estultificantes. A própria palavra economia evoca nele não a imagem do sustento do homem e a tecnologia que ajuda a assegurá-lo, mas lembra um conjunto de motivos particulares, atitudes peculiares e propósitos altamente específicos, que ele costuma chamar de econômicos, mesmo que sejam meros acessórios da economia real, devendo sua existência a uma interação efêmera de traços culturais. Não as características permanentes e palpáveis de todas as economias humanas, mas as meramente transitórias e contingentes lhe parecem essenciais. Está fadado a criar dificuldades para si mesmo onde, de outra forma, não há e a tropeçar em obstáculos facilmente evitáveis, cuja própria existência lhe é desconhecida. Em sua ignorância, não pode compreender nem as verdadeiras precondições de sobrevivência nem as formas menos óbvias de alcançar o possível. A obsoleta mentalidade de mercado é, a meu ver, o principal obstáculo para uma abordagem realista dos problemas econômicos da era que se aproxima (Polanyi, I977: xlvi). ${ }^{2}$

Se a teoria social contemporânea já vinha fazendo referência constante à obra de Karl Polanyi (I886-I964) desde a crise financeira de 2008, a pandemia 
do coronavírus colocou as ideias, os conceitos e os temas polanyianos ainda em mais evidência. Nesse ano que passou, a suposta oposição, reiterada por governantes conservadores e empresários, entre "vida" e "economia" ilustrava com clareza uma das grandes teses do historiador húngaro: os possíveis efeitos danosos de se conceitualizar e construir a economia como instância separada da política, da sociedade, da natureza e da vida. Além da obsolescência da mentalidade de mercado (Polanyi, 20I2), manifesta no número desnecessário de vidas perdidas em nome da abertura econômica, o recrudescimento do autoritarismo na última década também fez reviver outro tema caro ao autor: a relação conflituosa entre democracia e capitalismo (ou sociedade de mercado, como preferia Polanyi). Para Karl Polanyi, demandas democráticas necessariamente induziriam a crises do sistema capitalista ou a governos autoritários, visando à defesa da ordem econômica.

A complexidade dessas ideias e temas é apontada e explicada minuciosamente pelo economista político e teórico social Gareth Dale, professor da Brunel University (Reino Unido), o mais reconhecido estudioso da obra e da vida de Karl Polanyi, que entrevistamos em 6 de julho de 2019. A entrevista e os artigos que compõem este número especial reforçam a relevância contemporânea do trabalho de Polanyi, cuja obra vem sendo reexaminada recentemente por meio de diversas publicações nas áreas de economia política, sociologia econômica e antropologia da economia.

Nesse registro se incluem obras como Karl Polanyi: the life and works of an epochal thinker (Aulenbacher et al., 2020); Karl Polanyi: a life on the left (Dale, 20I6a); Reconstructing Karl Polanyi (Dale, 2016b); Karl Polanyi: the limits of the market (Dale, 20Io); Socioeconomia e democracia: a atualidade de Karl Polanyi (Hillenkamp \& Laville, 20I6); The power of market fundamentalism: Karl Polanyi's critique (Block \& Somers, 20I4); From The great transformation to the great financialization: on Karl Polanyi and other essays (Polanyi-Levitt, 2013); além de Market and society: The great transformation today (Hann \& Hart, 2009).

Essa recuperação do autor, incluindo algumas novas traduções para o inglês e outras línguas (a exemplo de Polanyi, 202 I), o preservam como um pensador fundamental para o entendimento da sociedade contemporânea e, em particular, de sua relação com questões econômicas. A persistência e renovação das políticas neoliberais (Plehwe, Slobodian \& Mirowski, 2020) e de austeridade fiscal (Blyth, 20I8) no Brasil e no mundo, a crescente tendência autoritária em democracias constitucionais (Snyder, 20I9) e a criação de bens ou mercadorias naturais ou informacionais (Birch \& Muniesa, 2020; Chiapello, Missemer \& Pottier, 2020) fazem sua extensa obra adquirir uma atualidade pouco usual.

Na entrevista, Gareth Dale reforça a ideia de que Karl Polanyi deve ser lido como um pensador complexo que, por sua trajetória e influências intelectuais variadas, explicou de forma brilhante as transformações da sociedade 
moderna no início do século XX, sem, contudo, se livrar de certas contradições e inconsistências teóricas significativas. Como autor da mais completa biografia do historiador (Dale, 20I6a), além de livros que apresentam sua obra criticamente (Dale, 20I0, 20I6b), Dale tem procurado complexificar a leitura dominante, de caráter social-democrata, da trajetória de Polanyi. Nessa interpretação soft do pensador húngaro, segundo Dale, o único objetivo político moderno realista e desejável seria uma forma de capitalismo regulado, no qual o sistema de mercado seria o mecanismo coordenador das economias modernas, embora complementado por instituições redistributivas e socialmente protetoras ( $\mathrm{Da}$ le, 20I6b). O movimento duplo, descrito na obra mais fundamental de Polanyi, A grande transformação, publicada originalmente em I944, consistiria em uma dinâmica de autoequilíbrio social, reduzindo as tendências predatórias do capitalismo laissez-faire e reinserindo (re-embedding) a economia na vida social.

Conforme Dale demonstra, Polanyi era um socialista mais radical, que não acreditava que o capitalismo pudesse ser aperfeiçoado a partir de cima, por meio de reformas político-sociais que protegessem a subsistência e a dignidade dos trabalhadores. Entretanto, apesar de almejar uma ordem socialista que suplantasse a capitalista, Polanyi não foi um anticapitalista revolucionário. Criticando simultaneamente as injustiças produzidas pela "sociedade de mercado" e as ambições de certa teoria econômica que pretendia explicar toda e qualquer sociedade como se fosse de mercado (a falácia economicista), Polanyi nunca se apoiou em uma teoria do processo de acumulação capitalista (Marx, 20I5), em favor da adoção implícita da teoria marginalista do valor austríaca - tema enfatizado na entrevista.

Essa é, segundo Dale, talvez a maior das contradições de Polanyi, e explica parte de sua dedicação ao estudo de sociedades e economias pré-modernas. Se a teoria econômica moderna parecia suficientemente capaz de compreender o sistema de mercado e o capitalismo - termo que ele não utilizava - poderia ser apreendido sem levar em conta a apropriação do valor do trabalho, o surgimento da sociedade de mercado liberal e suas contradições deveriam ser explicados por meio de uma abordagem comparativa com sociedades radicalmente diferentes.

O estudo dos sistemas de troca de sociedades pré-modernas (Polanyi, I966; Polanyi, Arensberg \& Pearson, 1957) pretendia, consequentemente, demonstrar a variedade de formas institucionais da vida econômica - ou da subsistência dos homens (Polanyi, 20I2). Apoiando-se nas primeiras etnografias de sistemas de trocas, além do primeiro volume de O capital (Marx, 20I5), como identifica Dale, Polanyi evidencia como a constituição da economia liberal, ou o sistema de mercado, se deu a partir da criação de mercadorias fictícias - a terra, o trabalho e o dinheiro, isto é, bens não produzidos com vistas ao intercâmbio mercantil. Foram essas mercadorias fictícias que criaram os desequilíbrios da sociedade liberal e seu desmoronamento a partir dos anos I920. 
Nesse caso, à fragilidade apontada pelo economista político britânico a respeito da construção teórica do modelo das mercadorias fictícias, apoiada na inversão da noção neoclássica de fator de produção, se soma o tratamento desigual que o autor de A grande transformação (Polanyi, 20I I) concedeu aos termos da equação, privilegiando o processo histórico entrelaçado de formação de mercados de terra e trabalho no caso britânico, e não apresentando propriamente uma análise sobre a formação do mercado de capitais - à exceção, obviamente, de sua preocupação com a unificação global dos mercados de moedas no âmbito do padrão ouro e suas consequências políticas catastróficas.

Dessa forma, Gareth Dale se debruça sobre o modo como a adoção, parcial e, em grande medida, pouco refletida, da teoria econômica austríaca se desdobrou em sua interpretação da relação entre o capitalismo e a democracia. Polanyi argumenta que o surgimento do fascismo e a crise dos anos I 930 foram consequência da ascensão democrática nos países ocidentais. A explicação, surpreendente, é que a influência da classe trabalhadora sobre o Estado e as medidas de proteção do trabalho prejudicaram o funcionamento do sistema de mercado, de acordo com a teoria de preços ortodoxa. Mesmo considerando o sistema de mercado inerentemente antidemocrático, Polanyi parece, contraditoriamente, concordar que o Estado de bem-estar social exacerbaria tendências autoritárias e ocasionaria o mau funcionamento da economia.

Assim, a ambiguidade característica da compreensão polanyiana dos contramovimentos políticos e sociais voltados para a circunscrição e o controle da expansão da esfera do mercado pode ser lida como um dos elementos representativos de uma teoria fundamentalmente aberta e, em grande medida, incompleta, a despeito de seu brilhantismo e da contínua oferta de recursos heurísticos para a investigação do capitalismo em sua forma contemporânea.

Nesse ínterim, tanto o Estado (Streeck, 20I9) quanto a corporação (Crouch, 20II) aparecem como elementos subteorizados. No primeiro caso, Dale argumenta que Polanyi possui uma teoria do Estado liberal particularmente eficiente na explicação das condições sociopolíticas que permitem o surgimento das mercadorias fictícias. Em sua elaboração, no entanto, a política enquanto esfera institucional submete a organização estatal e, consequentemente, as dinâmicas micropolíticas - e de classe - a ela internas, emergindo como um anteparo indeterminado e frágil diante do avanço do mercado.

Por outro lado, a desatenção às organizações econômicas, particularmente a corporação empresarial, que povoavam, no momento de sua análise, mercados nacionais cada vez mais oligopolizados, parece ainda menos sustentável diante dos efeitos combinados de sua ação na conformação da própria instituição mercantil. De maneira paralela, a prevalência concedida ao mercado, concebido como instituição por Polanyi, constrange as possibilidades de emergência de uma teoria da ação coletiva de tipo econômico, nada menos do que essencial. 
Em sua conjunção trágica nos regimes fascistas europeus - cada vez mais evidente até na literatura (Vuillard, 20I9), mas também nas democracias liberais do entreguerras -, Estados e corporações definiram a paisagem sociopolítica e econômica analisada por Polanyi, sem que o autor os considerasse de maneira aprofundada, e continuam a fazê-lo no mundo contemporâneo, como Dale indica. Dessa forma, sua concepção de Estado corporativo (Polanyi, 20I4: I98-I99), vinculada à interpretação das consequências negativas da interferência política no mecanismo de preços - a chamada areia na máquina -, pouco contribuiu para a compreensão das dinâmicas always embedded, isto é, de interpenetração contínua das esferas da política e da economia, chave da concepção contemporânea de enraizamento (Granovetter, 2007).

Não obstante, mais do que uma crítica dirigida a vulnerabilidades de sua construção, é fundamental tomar a análise polanyiana sobre a sociedade de mercado como um trabalho em processo, cujos fundamentos estabelecidos por Polanyi continuam a estimular a curiosidade acadêmica e a imaginação política em um sentido anticapitalista e plural.

Finalmente, encerrando a entrevista, Dale reflete sobre as ideias de Karl Polanyi a respeito de crescimento econômico e meio ambiente (Dale, Mathai \& Oliveira, 20I6), temas em que o economista político se tem aprofundado recentemente. Segundo Dale, mesmo que Polanyi não se tenha dedicado profundamente à investigação da relação entre a economia e a natureza, ele pode ser considerado um precursor das ideias sobre o decrescimento econômico, de acordo com sua visão crítica, "esquerdo-romântica" (Dale, 20I6b), do sistema capitalista.

O encontro entre um pesquisador inquieto e criativo como Gareth Dale e a obra de um dos pensadores mais influentes do século XX, Karl Polanyi, além de ensejar questionamentos específicos à trajetória e ao pensamento do autor, renovando seu entendimento e reabrindo possibilidades heurísticas, deu origem ao registro de entrevista aqui apresentado, assim como inspirou a reunião de uma série de trabalhos que, de maneiras diversas, seguem e reanimam a trilha analítica polanyiana.

Dessa maneira, à entrevista com Gareth Dale se segue um conjunto de quatro artigos, além de um registro de pesquisa e duas resenhas, que explicitam a abrangente e contínua relevância da obra de Karl Polanyi, bem como de abordagens e noções nela inspiradas, no que respeita à compreensão aprofundada de fenômenos econômicos, alguns já consagrados na literatura, outros de caráter emergente.

Os artigos aqui reunidos problematizam a centralidade da categoria embeddedness ou enraizamento e suas transformações na subárea da sociologia econômica; a relação entre mercadorias fictícias e processos state-led de mer- 
cantilização; as dinâmicas de contestação à mercantilização e sua relação com expansão do endividamento no capitalismo contemporâneo; assim como praças de mercado e suas expressões contemporâneas. Por sua vez, o registro de pesquisa e as resenhas apresentados explicitam dinâmicas apreensíveis, de modo complementar, como processos de disembededdness ou de desenraizamento econômico da sociedade, vinculando intimamente financeirização da vida e neoliberalismo, pedagogias econômicas e formas de reconstituição incessante das agências econômicas.

Anunciando o conjunto de trabalhos aqui reunidos, o artigo de Cristiano Fonseca Monteiro e Raphael Jonathas da Costa Lima, "Embeddedness and disembeddedness in economic sociology in three time periods", sintetiza um veio analítico estruturante da subárea da sociologia econômica e apresenta inovadora contribuição teórica para o desenvolvimento subsequente do campo e de áreas correlatas. O trabalho evidencia a duradoura relevância da noção, introduzida por Polanyi, de embeddedness - e de construções conceituais dela derivadas, como re-embeddeness e, especialmente, disembeddedness - para a análise sociológica dos fenômenos econômicos. A estruturação da abrangente e variada bibliografia mobilizada nos "tempos" da construção social da economia, do "movimento duplo" e do "embeddedness no disembeddedness" reatualiza a compreensão das relações entre Estado, mercado e sociedade, e desafia fronteiras entre correntes teóricas e axiomas bem estabelecidos de modo promissor, particularmente no que respeita ao progresso da investigação acerca da consolidação do neoliberalismo como quadro moral normativo, se sobrepondo à sua dimensão político-institucional.

"The unfinished development of the frontier: a Karl Polanyi reading of the conflict between the forestry industry, Mapuche communities and the Chilean State" é a contribuição de Tomás Undurraga e Felipe Marquez. O artigo se inspira no modelo polanyiano de transição à modernidade, centrado na relação entre os processos constitutivos das chamadas mercadorias fictícias e a emergência e consolidação do capitalismo, para analisar o conflito entre o povo Mapuche, o Estado chileno e o setor florestal. Baseando-se em documentos históricos e de mídia e em pesquisa etnográfica, a análise histórico-institucional da interação entre Estado, mercado e sociedade a partir do caso aponta, no entanto, a intensificação do conflito e da violência em anos recentes, ilustrando os obstáculos ao encerramento de "fronteiras" em periferias extrativas. Mais importante, o caso integra as dinâmicas de movimento (de disembeddedness) e contramovimento em termos de redistribuição e reconhecimento de forma relacional, demonstrando sua natureza híbrida e aberta a respostas diferenciadas, que chegam mesmo a integrar mecanismos de proteção social de caráter mercantil.

O trabalho de Felipe González-López, intitulado "Society against the market. The commodification of money and the repudiation of debt", por sua vez, 
articula interrogações apartadas, em grande medida, dos estudos acerca da ação coletiva, de um lado, e sobre financeirização, de outro. Assim, a proliferação de movimentos sociais de repúdio à dívida - este último tópico brilhantemente discutido pelo antropólogo recém-falecido David Graeber (20I6) -, que se segue à expansão do endividamento em diferentes contextos, recebe um tratamento analítico em termos do movimento duplo polanyiano. A partir de pesquisa bibliográfica e resultados de investigações etnográficas junto a movimentos de endividados no Chile, o autor apresenta contribuição inovadora em termos de variedades de repúdio ao endividamento, integrando as formas privadas e públicas de dívida às oportunidades e restrições à ação coletiva delas derivadas.

"Mercados e praças de mercado: Karl Polanyi e o capitalismo contemporâneo" representa a chave de ouro apropriada ao conjunto de artigos aqui reunidos. Marie France Garcia Parpet mobiliza ampla gama de contribuições teóricas e empíricas reunidas ao longo de sua trajetória, demonstrando a vivacidade da concepção polanyiana de "praça de mercado", diante de outras formas de institucionalização da troca, para a compreensão do "sistema de mercado formador de preços" na contemporaneidade. A problematização da noção de mercado e de suas múltiplas representações, remetendo à renovada capacidade heurística dos padrões institucionais e princípios de comportamento econômico polanyianos, permite, nesse sentido, acessar sua relevância contemporânea, particularmente em sua expressão digital, "a meio caminho entre firma e praça de mercado" e, especialmente, suas dinâmicas criadoras sui generis, formativas da mercadoria e de seu valor. Nesse sentido, produtoras dos contextos sociais nos quais a troca se dá por meio de posições de status dos participantes, do local (o virtual incluído) e do tempo do intercâmbio, assim como da objetificação da competição, praças de mercado integram circuitos mercantis policêntricos e globais na contemporaneidade. Em sua forma digital, sobretudo, essas instituições ensejam processos de valorização simbólica e de diferenciação e desclassificação sociais centrais para a compreensão do capitalismo.

O registro de pesquisa "Da educação ao empurrão: a participação das ciências comportamentais em programas de educação financeira”, de Viviane Fernandes, apresenta contribuição complementar aos textos reunidos nesta edição, discutindo um aspecto pouco explorado das recentes dinâmicas de "conquista" econômica do comportamento cotidiano. Nesses termos, a autora apresenta as condições e os resultados da pesquisa etnográfica realizada nas Conferências de Ciências Comportamentais e Educação do Investidor, uma expressão relevante da Estratégia Nacional de Educação Financeira (Enef). A pesquisa ilumina os esforços científicos, pedagógicos e políticos que informam a engenharia comportamental associada à (re)construção social do agente econômico, conferindo relevo às ciências comportamentais e sua incorporação sui generis da crítica polanyiana ao Homo economicus como base do contínuo aprimoramento e vitalidade de ontologias econômicas mainstream. 
Finalmente, duas resenhas complementam as reflexões apresentadas pelos artigos reunidos em torno da obra do pensador húngaro. A primeira delas, de Ana Beatriz Martins, intitulada "Sobre capitalismo, especulação e tempo", aborda o livro de Lisa Adkins The time of money, que materializa uma matriz teórica interdisciplinar e mobiliza aplicações empíricas robustas em torno da relação entre tempo e capitalismo, cuja inflexão em favor da ampliação da esfera financeira e seu domínio sobre a vida social atualiza e aprofunda a descrição polanyiana do processo de disembeddedness da economia da sociedade - argumento caro à literatura da economia política.

Em "Autoajuda financeira: governamentabilidade neoliberal e a produção de sujeitos", Elaine da Silveira Leite resenha a obra de Daniel Fridman Freedom from work: embracing financial self-help in the United States and Argentina, traduzida em espanhol como El sueño de vivir sin trabajar: una sociología del emprendedorismo, la autoayuda financiera y el nuevo individuo del siglo XXI. Enquanto o livro explicita o universo da autoajuda financeira e seus efeitos cotidianos a partir de incursões etnográficas na Argentina e nos EUA, a resenha destaca sua elegante análise da construção social do sujeito econômico, articulando o papel normativo do neoliberalismo e o enraizamento cultural da economia. O enquadramento embeddedness no disembeddedness não é, certamente, acidental.

Por fim, o conjunto aqui reunido expressa a dedicação à análise socioantropológica sobre a vida econômica, inspirada e em diálogo com a obra de Karl Polanyi e, nesses termos, se afirma como uma contribuição ao entendimento e à construção de sociedades mais democráticas politicamente e igualitárias em âmbito econômico. Agradecemos a todas e todos, autoras/es, pareceristas, editoras/es, colegas e leitoras/es de S\&A, que apoiaram e tornaram possível sua materialização.

Desejamos a todas e todos uma leitura proveitosa! 


\section{ENTREVISTA COM GARETH DALE ${ }^{3}$}

Rodrigo Santos Muito obrigado por estar hoje aqui conosco e nos conceder esta entrevista. Para dar início à conversa, poderia nos explicar como sua trajetória o levou ao trabalho de Karl Polanyi?

Gareth Dale Minha primeira grande pesquisa foi sobre a Revolução da Alemanha Oriental em I989. Na época eu morava lá, e foram tempos emocionantes aqueles. Voltei para casa com muito material nas mãos e a mente cheia de perguntas sobre o que havia acontecido. Então, escrevi minha tese de doutorado sobre o tema, posteriormente publicada em livro (Dale, 2007). Após alguns anos trabalhando naquilo, comecei a procurar outras coisas interessantes para fazer e pesquisar. Estava cansado do meu tema, com o qual já trabalhava há cerca de I4 anos. Alguns acadêmicos, de maneira mais sistemática, desenvolvem, se aprofundam e ramificam o tópico principal para outras áreas; eu queria dar uma guinada para algo completamente diferente.

Percebi que o trabalho de Karl Polanyi (I886-I964) estava em evidência. Parecia que ele estava sendo muito citado, mas não muito entendido em profundidade. Algumas de suas teses também me soavam muito particulares e bem distintas da minha maneira de entender a história do século XX. Por exemplo, a ideia de Polanyi de que a década de I920 havia sido conservadora e a de 1930 revolucionária era o inverso da minha. Sendo assim, fui envolvido por aspectos menos comuns de seu trabalho. Também me identifiquei com alguns outros aspectos da sua perspectiva, particularmente com um certo romantismo, um pavor sobre o que capitalismo estava fazendo com o mundo, embora Polanyi não costumasse usar a palavra capitalismo. E sua capacidade de escrever uma ciência social com uma visão ampla, atitude hoje em dia quase desencorajada, que eu também achava bastante impressionante. Sendo as sim, havia elementos em Polanyi que acreditei serem impressionantes e fascinantes, embora outros me soassem estranhos. Em alguns casos o modo como era citado me parecia inadequado. Por esses motivos passei a pesquisar seu trabalho e obtive uma bolsa para estudar os arquivos de Polanyi. ${ }^{4}$ Uma vez dentro dos arquivos, fui contaminado pelo vírus, e surgiu uma série de questões, insights surpreendentes tomaram conta de mim etc. Esse trabalho foi bem divertido. Visitei, naturalmente, outros arquivos, na Hungria, nos EUA, no Reino Unido, mas é nos arquivos Polanyi em Montreal que se encontra a maior parte dos tesouros...

R.S. Quais são os principais benefícios de se aprofundar no trabalho de um só autor, tendo em conta que, de uma perspectiva metodológica, há uma enorme diferença em tentar seguir uma abordagem mais temática? Ao se dedicar tanto a um autor, e se tornar expert no seu trabalho, é possível tornar-se uma es- 
pécie de guia, ou alguém que deve ser lido por aqueles que desejam adentrar a obra de Polanyi? Então, como é essa experiência?

G.D. Bem, depende... para mim, eu estava seguindo o trabalho de um autor sensacionalmente talentoso, um verdadeiro intelectual polímata, renascentista, trabalhando com um escopo disciplinar que era, em termos gerais, o mesmo que o meu, mas, obviamente, no caso dele, em um nível muito mais avançado. Então, poder segui-lo por esses variados terrenos era, com certeza, intrinsicamente interessante, como se alguém investisse tempo estudando também Karl Marx ou Max Weber. Simples assim, eu diria.

De certo modo isso foi motivado pela emoção de eu ter descoberto tanta coisa nos arquivos. Sendo assim, por um lado, foi puramente a emoção intelectual de descobrir que algumas preconcepções da literatura eram simplistas ou errôneas, que poderiam ser novos ângulos que nos ajudariam a entender, sabe... É como encaixar peças de um mesmo quebra-cabeças de maneira diferente da anterior. Já por outro lado, também existe uma política nesse fazer, e meu trabalho sobre Polanyi é, talvez, entre minhas áreas de atuação, aquele com menos motivação ativista. Portanto, como na Alemanha Oriental eu estava envolvido na revolução, então meu trabalho sobre esse país evoluiu organicamente a partir daí. Meu trabalho atual sobre crescimento e meio ambiente é motivado por uma obsessão com relação à mudança climática e à crise ambiental, em geral, e pelos dilemas do crescimento econômico. Meu trabalho sobre Polanyi, porém, foi consideravelmente mais intelectual, embora também inclua uma alusão política.

Gustavo Onto Como, na sua opinião, esse trabalho também pode ser político?

G.D. Temos o fato de que a leitura dominante, mainstream, de Polanyi tem sido, por algum tempo, razoavelmente social-democrata, uma interpretação soft, como defino no meu livro (Dale, 20I6b). Mas temos também o que podemos chamar de leitura de esquerda de Polanyi, a interpretação hard, associada à sua filha, Kari Polanyi-Levitt, 5 entre outros. Não sendo eu um adepto intelectual de Polanyi, meu interesse nele parece um tanto estranho, mas eu me identifico, até certo ponto, com suas ideias, e, no meu entender, no período entreguerras, ele foi um socialista mais radical do que em geral o consideravam. Tendo dito isso, não acho que ele foi um socialista revolucionário, da maneira que eu entendo esse posicionamento, como no esquema marxista. Alguns sugerem que ele teria sido um socialista revolucionário, porém eu discordo deles. Então, tínhamos vários debates e eu tomava partido neles, o que muito se infunde no meu trabalho sobre Polanyi, naturalmente. Estou sugerindo que ele não é um anticapitalista revolucionário de um modo consistente, e isso, para mim, dada a minha tradição marxista, é uma das causas da fragilidade de seu trabalho. 
R.S. Em que sentido Polanyi não era um pensador anticapitalista revolucionário?

G.D. Acima de tudo, em sua obra não há qualquer concepção de capitalismo ou acumulação de capital, crucialmente. Na minha opinião, a concepção marxista é fundamental para entendermos o mundo moderno e, caso você não compreenda essa dinâmica, de fato estará perdendo algo muito essencial. Eu também estava preocupado em defender o radicalismo de Polanyi contra alguns que tentavam domá-lo ou suavizá-lo, especificamente contra aqueles para os quais, por exemplo, o movimento duplo ${ }^{6}$ é somente um tipo de mecanismo homeostático de regulação, de modo que, se ao mercado for permitido ir muito longe, então a sociedade reagirá pela intervenção de partidos social-democratas e da ação dos sindicatos, fazendo com que o capitalismo retorne, novamente, ao equilíbrio. Algumas pessoas leram Polanyi dessa maneira, e eu acredito que isso não seja muito legítimo.

G.O. Mas você não estudou somente o trabalho escrito de Polanyi. Você escreveu uma importante biografia do historiador. Como esse trabalho reforça sua interpretação sobre suas ideias?

G.D. Eu acabei escrevendo três livros sobre Polanyi e eles se resumem em uma análise de sua vida e época e à relação entre, obviamente, sua obra e minha crítica. Levando em consideração os materiais que coletei nos diversos arquivos, mesmo que eu tivesse colocado todos em um único livro, ele seria gigantesco e excessivo. Sendo assim, acabei dividindo o material na ênfase de sua vida e época... Os três aspectos estão presentes nesses livros, obviamente, mas o foco do publicado pela editora Polity (Dale, 20Io) é no seu trabalho; o enfoque do livro da Columbia University Press (Dale, 20I6a) recai sobre sua vida e época; enquanto o foco do publicado pela Pluto Press (Dale, 20I6b) é a minha crítica, ou melhor, talvez não o foco - a palavra é muito forte, mas dou um pouco mais de ênfase à crítica nesse trabalho. Na verdade, é um livro só, mas como teria muito material, foi dividido em três.

R.S. É bastante comum que comentaristas apresentem a obra de Polanyi como algo mais consistente do que você faz transparecer e, portanto, é tão instigante ler o seu trabalho, que nos traz uma série de possibilidades interpretativas. Você acha que a trajetória pessoal dele demonstra mais divergência e diversidade em relação às interpretações tradicionais de Polanyi?

G.D. Somos todos inconsistentes, e isso acontece, provavelmente, porque nós escrevemos por longos períodos de tempo, nos transformamos como indivíduos, e o mundo ao nosso redor também se transforma. Então, considerando isso, algumas das inconsistências de Polanyi são esperadas, e assim, é claro, grandes 
teóricos sociais sofrem importantes influências de diversos tipos de acadêmicos, ativistas etc. Eles conduzem seus trabalhos em diferentes direções e exageram, talvez, na aparência de consistência. No caso de Polanyi também, sabemos que ele, talvez mais do que Marx, viveu períodos de crises sociais e guinadas violentas, envolvendo revoluções, guerras e conflitos etc., sendo isso parte do motivo para suas movimentações intelectuais.

Essa é a razão pela qual precisamos de uma biografia que entenda algumas de suas inconsistências e a evolução de seu pensamento. Além disso, porém, tenho uma certa fascinação por essas tensões de seu passado, isto é, aquelas que enfatizo na biografia, envolvendo seu pai e mãe e as diferentes culturas que eles representam, assim como as várias influências que ele tenta condensar, influências de Marx, sobre a alienação do fetichismo da mercadoria,? e que ele normalmente entende muito bem... aqueles poucos capítulos de $\mathrm{O}$ capital. $\mathrm{O}$ restante, que ele não compreende profundamente, é tratado a partir da combinação de conceitos, de modo geral, de Marx, com categorias da economia austríaca, que são, na verdade, um tanto quanto incompatíveis, mas que ele tenta unir em seu trabalho. Esses elementos contraditórios, de sua própria formação, são o que o tornam um grande pensador. No entanto, algumas das maneiras por meio das quais ele tenta reconciliar, até certo ponto, tradições incompatíveis, acabam por induzir certas fragilidades, perceptíveis em seu trabalho.

R.S. Seguindo esse caminho, como a teoria econômica e, particularmente, a teoria econômica neoclássica, se infiltra no pensamento de Polanyi? Sendo esse um elemento marcante de seu livro, e concordando com a ideia de que Polanyi não situou o capital e o processo de acumulação no centro de seu pensamento, de que maneira a economia austríaca influenciou algumas hipóteses polanyianas sobre o capitalismo?

G.D. Bem, ele é certamente muito crítico da economia burguesa pela sua propagação da falácia economicista, ${ }^{8}$ por suas suposições implícitas de que algo como uma sociedade baseada na troca mercantil existiu ao longo da história e de que é através dessas lentes que devemos analisar todas as formas de comportamento econômico, sejam elas situadas na Suméria antiga ou na Viena moderna; mas acabou adotando alguns dos princípios da economia austríaca ou economia neoclássica, a exemplo da teoria marginalista do valor. Como argumentei em Reconstructing Karl Polanyi (Dale, 20I6b), ele rejeitou a teoria marxista do valor com base em sua essência ricardiana, mas, ao fazer isso, ele interpreta Marx de maneira errada... Polanyi acaba aceitando totalmente a teoria do valor da economia austríaca.

Ele concordava com Franz Oppenheimer (I864-I943) ${ }^{9}$ quanto à ideia de que a economia neoclássica era um modo essencialmente válido de analisar o comportamento mercantil, mas divergia dele no sentido de que Oppenheimer foi muito longe ao supor que essa abordagem fosse autossuficiente para ana- 
lisar a economia. Dessa forma, esquecemos que a economia é criada por seres humanos, que são seres culturais e espirituais; são, acima de tudo, seres sociais, o que requer que toda economia seja sempre considerada em sua singularidade histórica, cultural e política, como um todo orgânico.

R.S. Esse ponto é muito interessante, porque a teoria marginalista é um modo subjetivo de compreender o valor, e Polanyi estabelece um tipo de teoria fundamental sobre como terra, dinheiro e trabalho não são commodities naturais, o que implica alguma contradição. Se ele quisesse fazer isso e se tivesse transitado pela teoria marxista com esse objetivo, talvez pudesse ter construído uma teoria do valor de inspiração mais materialista. Como você acha que ele pôde conciliar estas interpretações tão diferentes, a teoria subjetiva do valor e a ideia de mercadorias fictícias?

G.D. Não irei sugerir uma resposta, pois não sou um polanyiano. Meu trabalho tem sido como crítico simpatizante e solidário, assim como de exegese, para explicar a sua obra da maneira que eu a entendi. Quando me pedem para redesenhar sua teoria, para superar algumas dessas contradições, isso já ultrapassa o que eu sou capaz de fazer como um não polanyiano.

G.O. Acho que podemos começar por esmiuçar o problema do dinheiro, ou da moeda, em Polanyi. Por que ele achava que o dinheiro não devia ser considerado uma verdadeira mercadoria?

G.D. Porque o dinheiro é essencialmente um mecanismo socialmente construído para permitir a contabilidade social, basicamente, sob o ponto de vista de Polanyi, e isso é o cerne da questão. Além disso, serviria para intermediar relações entre pessoas desconhecidas etc. O dinheiro, porém, foi tratado, na opinião dele, nas sociedades liberais do século XIX como se fosse uma mercadoria, como se a moeda fiduciária fosse, simplesmente, um novo formato dado ao ouro. Por isso foi permitido que esse dinheiro flutuasse como qualquer outra mercadoria, de acordo com as mudanças das condições do mercado.

Como vocês sabem, algumas das ideias mais interessantes de Polanyi, eu acho, têm relação com sua análise detalhada do desmoronamento da civilização liberal no início do século XX. E sua principal preocupação foi sobre o modo como o padrão ouro restringia a autonomia dos governos, tendo como resultado uma volatilidade econômica traduzida em depredações sociais, sobretudo desemprego em massa, nas décadas de I920 e I930. Isso foi consequência do tratamento do dinheiro como se fosse uma mercadoria, quando de fato era uma ferramenta social para permitir a contabilidade econômica, entre outras funções descritas por sociólogos e antropólogos. 
G.O. Então, o dinheiro era uma das divergências que ele tinha com os austríacos, que o consideravam essencialmente uma mercadoria. Ele, por outro lado, estava se alimentando dos trabalhos etnográficos que lia, sobre como o dinheiro poderia ter objetivos especiais em diferentes sociedades. Para ele, isso devia, necessariamente, ser levado em consideração?

G.D. Sim, de várias maneiras, sem dúvida. Não gostaria que achassem que estou sugerindo que ele era, seriamente falando, próximo dos austríacos. Os aspectos da teoria austríaca que ele carregou formam, em parte, a razão de sua inabilidade, na minha opinião, de teorizar o capitalismo. Existe uma versão austríaca da economia capitalista, como se pudéssemos descrever o capitalis mo como um "momento", simplesmente o puro momento da troca ou câmbio. E aqui, novamente, está parte de minha crítica a Polanyi. Pois não acho útil conceber o sistema econômico da modernidade como uma simples ampliação desse momento da troca, como o mecanismo de troca. Precisamos introduzir o Estado, por exemplo. Nesse sentido, ele faz isto, apresentando uma brilhante teoria do Estado liberal; uma de suas mais importantes contribuições é essa análise.

Mais uma vez, entretanto, acho que essa ambiguidade, as tensões e contradições internas de seu trabalho sobre essa questão... algumas das implicações de seu trabalho sobre o Estado liberal não foram extraídas. Isso significa que não basta dizer que o Estado liberal é crucial para que se estabeleça uma estrutura para o que ele chama de mercadorias fictícias. Mas, eu diria, mais do que isso, o Estado liberal está continuamente interferindo na gestão da sociedade, no interesse, acima de tudo, da acumulação de capital. Há um grau muito forte de integração entre os quadros e a lógica... entre o Estado e o capital. Porém, ele não discute isso, principalmente pela sua tradicional insistência liberal na demarcação de diferentes subsistemas. Podemos observar isso mais acentuadamente em sua fase pluralista, mas também em grande parte de seu trabalho.

G.O. Poderia explicar um pouco mais esse ponto, isto é, essa insistência de Polanyi na separação entre esferas ou subsistemas sociais?

G.D. Outro dia eu entrevistei alguém que está trabalhando muito com povos indígenas na região de Belo Monte, que me contou que a Companhia ${ }^{\text {Io }}$ que está construindo a represa também está construindo escolas como uma moeda de troca junto à população indígena. A pessoa entrevistada tinha como principal função explicar para a população indígena, arrasada e desnorteada, o que estava acontecendo ao redor da represa, o que era tudo aquilo. Eles não estavam familiarizados com conceitos como Estado e empresas, e uma das principais perguntas que faziam era: "Onde começa o Estado e onde acabam as empresas? 
Porque vemos a empresa construindo as escolas. Então, qual é a diferença?" Existe uma tendência, a meu ver, no capitalismo, de continuar a combinar esses princípios, essas instituições. Polanyi se identifica com os austríacos, nesse sentido, por visualizar linhas de separação bem delimitadas entre elas.

R.S. Gostaria que você comentasse um pouco sobre como ele, sendo tão atento a essas instituições, especialmente o mercado, não se detém nas empresas em uma época na qual essas organizações já eram muito poderosas. Isso remete um pouco à crítica de Colin Crouch (20I I) de que a sociologia econômica discutiria em excesso o mercado, quando deveria estar se dedicando mais às empresas e a suas expressões transnacionais. Então, como você vê essa questão?

G.D. Para mim, esse é um dos paradoxos no trabalho de Polanyi, porque ele é tão interessado nas instituições, um velho institucionalista, em certo sentido, e, mesmo assim, ele não observa as instituições dentro da economia, de um modo mais focado, como você diz. Ele desconsidera a sociologia das empresas ou a sociologia econômica.

G.O. Acredito que isso se deva aos trabalhos que ele estava lendo na antropologia e como eles buscavam criticar o pensamento econômico. A crítica assumia, de certa forma, algumas prioridades predefinidas pelos economistas. Por exemplo, Bronislaw Malinowski, em seu período na London School of Economics (LSE), buscava sustentar argumentos no que diz respeito ao comportamento econômico humano em oposição aos economistas. Ao tomar a teoria econômica como referência, mesmo que crítica, os antropólogos eram induzidos a um caminho, a certos temas, como o "mercado" ou o "comportamento autointeressado". Sendo assim, Polanyi poderia estar preso na mesma discussão, na mesma forma de crítica que desenvolviam naquela época. Com exceção de Marcel Mauss (20I7), talvez, as empresas eram um tema secundário para a maioria dos antropólogos, como Malinowski.

G.D. Esse é um ponto muito interessante. Não havia pensado nisso, mas me parece bem persuasivo. Porque podemos compará-lo a Joseph Schumpeter (I 883I950) ${ }^{\text {II }}$ que, na época, estava muito interessado no desenvolvimento das empresas e o que aquilo significava para a lógica econômica. Para ser justo com Polanyi, alguns de seus trabalhos mais envolventes e inovadores implicam a recuperação de insights da antropologia econômica das sociedades pré-modernas para o nosso próprio entendimento do capitalismo moderno. Esse é um tipo de crítica romântica da modernidade que acho bem inspiradora, mas durante o processo algo se perde, e aí colocamos o dedo na ferida... seu argumento sobre as empresas... 
R.S. Talvez possamos estender um pouco essa ideia de oposição entre economia e política e, especialmente, a dicotomia mercado versus democracia, que serve de inspiração a Polanyi e tem sido apontada por acadêmicos contemporâneos. Wolfgang Streeck (20I9), por exemplo, argumentou que a convivência entre democracia e mercado seria temporária. Como você vê a relação entre mercados e democracia hoje em dia?

G.D. Começando pelo Streeck, que você mencionou, acho o trabalho dele inestimável de várias maneiras e, de fato, muito interessante. Porém, ele tende a insistir que a única arena ou estrutura natural e realisticamente possível para a democracia política é o Estado-nação. Mas o Estado-nação é um produto e um aliado do capitalismo. Estados-nação surgiram juntos e em conexão, criados sob o impacto de mudanças sociais radicais e fundamentais que ocorreram com a ascensão do capitalismo. A dissolução da sociedade estamental, o movimento em direção à força de trabalho assalariada etc. E em um mundo cada vez mais globalizado, é claro, as limitações de tal estruturação nacional da democracia são completamente visíveis.

G.O. Como podemos comparar o que Polanyi diz sobre as relações entre mercados e democracia com as ideias de Streeck? Para quem não leu o seu livro, qual seria a diferença?

G.D. Então, Polanyi fez alguns trabalhos muito interessantes no período entreguerras. Bem, parte da sua análise sobre os, assim chamados, efeitos disruptivos que levaram à Grande Depressão e à escalada do fascismo remete à ascensão da democracia política, que teria prejudicado o funcionamento normal do capitalismo. Isso porque, repentinamente, o Estado não é apenas influenciado pelos capitalistas, que o usam para interesses próprios, mas também o é pela classe trabalhadora. Isso nos remete ao argumento de Polanyi sobre a "areia na máquina", a ideia da reivindicação do trabalhador... Como o Estado é forçado a concessões em questões de bem-estar social, o funcionamento do mercado e do mecanismo de precificação torna-se engessado - o que prejudica a máquina do mercado.

Bem, existe um problema básico nessa teoria, que é um dos aspectos austríacos do Polanyi, obviamente. Ele acredita que o mercado tem que ser protegido das reivindicações da classe trabalhadora para funcionar com eficácia. Mas, sabemos que, naturalmente, após a Segunda Guerra Mundial, o capitalismo estava em geral bastante regulado, e, no entanto, cresceu muito rapidamente, ficando esse período conhecido como a Era de Ouro. Em alguns países, talvez não aqui no Brasil, também foi uma era bem democrática. Então, essa tese se depara com problemas nessa parte.

Em termos políticos gerais, no entanto, todos à esquerda - Polanyi, marxistas, qualquer um - defendem a ideia de que os mercados são radicalmente antide- 
mocráticos. Por quê? Porque eles concentram o poder nas mãos daqueles que possuem a riqueza, e existem fortes tendências para a exacerbação disso, no sentido de efeitos antidemocráticos que se difundem por toda a nossa sociedade.

R.S. No Brasil, tivemos um ciclo de quase i5 anos de governo do Partido dos Trabalhadores (PT) que, com uma plataforma social-democrata, buscou reconciliar a ideia de que democracia eleitoral e o pleno funcionamento dos mercados são compatíveis, com efeitos políticos particularmente negativos. Nesses termos, quais as perspectivas para a social-democracia e qual seria o tipo de política eleitoral de esquerda para os próximos anos, visto que essa suposta compatibilidade, ao menos em Polanyi, desconsiderava a interdependência e a concorrência intercapitalistas?

G.D. Movimentos democráticos aparecem e normalmente, em suas fases iniciais, tendem a ser mais baseados em mobilizações; eles são erguidos por movimentos de massa; no caso do Brasil, o Sindicato dos Metalúrgicos [do $A B C$ ] e suas intensas greves gerais. Quando um novo partido social-democrata é fundado, normalmente e quase sempre, apresenta um novo projeto, não a "velha social-democracia", mas algo bem novo, frequentemente relacionado a algo não distinto do tipo de socialismo corporativo no qual Polanyi estava envolvido no início dos anos I920: um compromisso entre democracias econômica e política, porém sem questionar a neutralidade básica do Estado.

Apesar de ser de esquerda e ligado a movimentos sociais, é isso que faz dele o partido essencialmente social-democrata em seu jogo estratégico. Seguindo essa lógica, procura estabelecer-se como o partido dominante capaz de governar e, também, é obrigado a buscar coalisão com os partidos políticos e as instituições existentes. Estes, por sua vez, estão presos dentro do funcionamento da sociedade capitalista e, pouco a pouco, a natureza popular do movimento desaparece e o partido transforma-se em algo burocratizado, de modo que o papel dos quadros se torna mais e mais dominante.

Estou falando aqui basicamente da história do PT, mas também de outros partidos em situações similares. E aí nos pegamos esquecendo o compromisso com a democracia econômica, o que o PT sob Lula fez muito rapidamente. Mas se encontrava lá fortemente no início, porque expressava o tipo de ideias críticas ao sistema que tendem a ser lançadas por movimentos de massa de trabalhadores comuns, quando sentem que são capazes de penetrar a camada sufocante da sociedade burguesa e realmente fazer diferença. Quando isso acontece, temos ideias muito radicais vindo à tona e sendo canalizadas nas organizações social-democratas, como o PT... e depois eles se reconciliam, vocês conhecem a história...

Polanyi era claramente parte desta tradição radical social-democrática da esquerda, mas entendo que ele não tinha os instrumentos de autocrítica, 
da crítica dessa tradição, porque ele acreditava fundamentalmente na neutralidade de classe do Estado. Exceto no caso do fascismo, em que o Estado é, na sua visão, controlado pela classe capitalista. De modo geral, entretanto, nas democracias liberais o Estado é, na visão de Polanyi, neutro com relação à classe e ao sistema, não estando subordinado, significativamente, aos capitalistas.

Você mencionou a competição intercapitalista. Acho que parte da sua pergunta se refere ao fato de que já que o mundo todo é capitalista e dado que os mesmos Estados-nações do mundo estão subordinados ao capitalismo, qualquer desafio a ele será também um desafio a outros Estados. Como explicar isso? Bem, Polanyi encontra inspiração na União Soviética, que dava a impressão de estar tentando se desatrelar do mercado mundial e constituir-se como uma entidade socialista separada. Polanyi era crítico com relação à União Soviética, de várias maneiras, mas acreditava que aquilo era, essencialmente, o que deveria ser feito.

Não concordo com ele sobre isso. Quanto mais trabalhos vemos sobre a União Soviética, e estou aqui pensando, por exemplo, no livro de Sanchez-Sibony (20I9) sobre a "globalização vermelha", fica cada vez mais claro e irrefutável que a União Soviética estava muito integrada no mercado mundial e a ideia que era uma autarquia é um mito. Obviamente, naquela fase do capitalismo, a maioria dos países era mais autárquica que hoje em dia, porém a União Soviética não era uma autarquia.

Polanyi acreditava que o governo do Partido Comunista na União Soviética sob Stalin representou a vitória da política e, portanto, na sua visão, possivelmente, de um conjunto de princípios universais de base comunitária, por meio do qual ele acreditava que a política estava assumindo o controle da sociedade. Minha opinião é oposta, de modo que, no final da década de I920, o próprio Partido Comunista foi "economicizado" e se submeteu ao princípio da rápida acumulação de capital.

R.S. É possível pensar em algum tipo de Estado e de política que compatibilize crescimento econômico e redução da desigualdade no capitalismo contemporâneo a partir dessa crítica a Polanyi?

G.D. De várias maneiras, é possível ler Polanyi como um defensor tanto do crescimento como do decrescimento. Acho interessante, pois apesar de não ser um defensor do decrescimento, isto é, não estando de acordo com o projeto do decrescimento, acredito que a questão do crescimento está se tornando, reconhecidamente, um grande problema e desafio.

Dessa forma, é possível interpretar Polanyi quanto à União Soviética a partir de seu apoio ao Estado e a Stalin, que estavam apresentando suas credenciais socialistas ao dirigir uma taxa de crescimento muito rápida. Por outro lado, porém, podemos lê-lo como o precursor do decrescimento, com sua ên- 
fase na necessidade de, como ele chama... Esta díade em A grande transformação (Polanyi, 20II), a oposição entre habitação e progresso, ${ }^{12}$ remete a seu tipo de crítica semirromântica do capitalismo, que se opõe ao progresso à custa da habitação. Desse modo, o equilíbrio tem que ser restabelecido, de maneira que a habitação deva ser o princípio central que nos guiaria para criar uma nova economia, em detrimento do progresso e do crescimento.

G.O. Por acaso seu interesse mais recente nas mudanças climáticas e no crescimento econômico também está relacionado ao trabalho de Polanyi? Em A grande transformação (Polanyi, 20I I), o argumento de que a terra era uma mercadoria fictícia está muito relacionado à ideia de que, não sendo produzida pelo homem, a terra é uma dádiva da natureza. Essa interpretação da relação entre o capitalismo e a natureza ou entre a economia e a natureza é relevante na sua reflexão?

G.D. Não. Meu trabalho sobre crescimento não teve decorrência lógica de meu trabalho sobre Polanyi. Eu estava simplesmente analisando indícios de mudança climática e de crise ambiental e fiquei muito preocupado. $O$ assunto do crescimento era, na época, uma questão mais acadêmica, que atraiu meu interesse. Dito isso, eu realmente acho Polanyi muito divertido, inspirador, no que diz respeito à sua crítica sobre o que a sociedade de mercado, na sua visão, faz com a natureza. Esse entendimento da natureza como objeto de exploração é muito forte, mas acho que ele, na verdade, não entra muito em detalhes sobre essa questão.

De fato, mesmo sua abordagem geral sobre as mercadorias fictícias carece de teorização completa. Sendo assim, a terra, o trabalho e o dinheiro são as mercadorias fictícias frequentemente consideradas, mas acredito que, mesmo a seu modo, seria melhor observar dois níveis diferentes. Ele está considerando a famosa trindade das fábricas manufatureiras da economia burguesa, terra, trabalho e capital... terra, trabalho e capital! E isso corresponde a natureza, seres humanos e dinheiro.

Acho que haveria escopo para que ele tivesse estruturado isso de maneira mais sistemática, e, assim, seria possível dizer que a natureza sob o capitalismo se torna simplesmente terra e, no pensamento econômico burguês, o que reflete o sistema econômico e sua ideologia, fazendo da terra simplesmente um objeto de exploração. Os seres humanos, nessa sociedade, se tornam simplesmente força de trabalho e objetos de exploração. O dinheiro nessa sociedade, em vez de ser um sistema complexo de contabilidade e mediação entre diferentes interesses econômicos etc., torna-se simplesmente capital, em sua infinita autoexpansão no interesse daqueles que o possuem.

Acredito que, se colocada nesses termos, teria sido uma teoria muito mais robusta e acho que podemos ler Polanyi legitimamente como tendo visto isso, mas teria sido mais útil caso ele tivesse demonstrado de maneira mais 
clara e também se dedicado mais à questão do meio ambiente, porque o trabalho do Polanyi tem um viés ambientalista crítico, porém modesto. Quero dizer, comparado a Marx; quanto mais material é publicado sobre Marx e o meio ambiente, especialmente o livro recente de Kohei Saito (20I7), que é simplesmente brilhante, e Bellamy Foster (2005), obviamente, fica mais evidente para nós. Marx e Engels também estavam pensando em detalhe a respeito da ação do capitalismo sobre o meio ambiente. Polanyi tem uma visão crítica similar sobre o que a sociedade de mercado fazia com o meio ambiente, mas é uma pena que ele não tenha se aprofundado mais. A menos que eu tenha deixado escapar alguma coisa dos Arquivos e um dia alguém descubra. Será maravilhoso se isso acontecer.

R.S. Bem, posso dizer que nossa conversa foi muito agradável e nos proporcionou uma excelente entrevista.

G.O. Sim, sem dúvida. Muito obrigado.

G.D. Ótimo!

Rodrigo Salles Pereira dos Santos é professor adjunto do Departamento de Sociologia, vinculado ao Programa de Pós-Graduação em Sociologia \& Antropologia (PPGSA), Universidade Federal do Rio de Janeiro (UFRJ). Dentre suas publicações, destacam-se: "New developmentalism in Brazil? The need for sectoral analysis" (com Heike Doering e Eva Pocher); e "The global production network for iron ore: materiality, corporate strategies, and social contestation in Brazil" (com Bruno Milanez).

Gustavo Gomes Onto é doutor em antropologia social pelo Museu Nacional (PPGAS, UFRJ) com período sanduíche na École Normale Supérieure (França). É mestre em sociologia pela Columbia University (EUA) e em administração pública e governo pela Fundação Getulio Vargas (Eaesp). Atualmente é pesquisador de pós-doutorado Capes do Programa de Pós-Graduação em Sociologia e Antropologia (PPGSA). Dentre suas principais publicações, destacam-se "Competition on paper: artifacts of visualization in antitrust policy" e "O agente econômico e suas relações: identificando concorrentes na política antitruste". 


\section{NOTAS}

I Os autores agradecem à Fundação Carlos Chagas Filho de Amparo à Pesquisa do Estado do Rio de Janeiro (Faperj) e à Coordenação de Aperfeiçoamento de Pessoal de Nível Superior (Capes), pelo apoio financeiro recebido através do Edital Jovem Cientista do Nosso Estado, 2017 (E26/203.218/2017) e do Programa Nacional de Pós-Doutorado (88882.3166I4/20I9-oI), respectivamente.

2 No original: "Our social thinking, focused as it is on the economic sphere, is for that very reason ill equipped to deal with the economic requirements of this age of adjustment. A market-centered society such as ours must find it hard, if not impossible, justly to gauge the limitations of the significance of the economic. For once man's everyday activities have been organized through markets of various kinds, based on profit motives, determined by competitive attitudes, and governed by a utilitarian value scale, his society becomes an organism that is, in all essential regards, subservient to gainful purposes. Having thus absolutized the motive of economic gain in practice, he loses the capacity of mentally relativizing it again. His imagination is bounded by stultifying limits. The very word economy evokes in him not the picture of man's livelihood and the technology that helps to secure it, but recalls instead a set of particular motives, peculiar attitudes, and highly specific purposes, all of which he is used to calling economic, even though they are mere accessories to the actual economy, owing their existence to an ephemeral interplay of cultural traits. Not the permanent and abiding features of all human economies but the merely transitory and contingent ones appear to him as the essentials. He is bound to create difficulties for himself where otherwise there are none and stumble over easily avoided obstacles whose very existence is unknown to him. In his ignorance, he can grasp neither the true preconditions of survival nor the less obvious ways of attaining the possible. The obsolete market-mentality is, as I see it, the chief impediment to a realistic approach to the economic problems of the oncoming era" (Polanyi, 1977: xlvi).

3 Algumas frases interrompidas pelo entrevistado foram suprimidas quando comprometiam a inteligibilidade da 
leitura, sendo outras mantidas, seja por não afetar a compreensão, seja por sua relevância, aparecendo seguidas por reticências. Expressões idiomáticas e função fáticas, em geral, foram mantidas, compondo o estilo do orador.

4 O Karl Polanyi Digital Archive (KPIPE) é o principal repositório de material arquivístico sobre a vida e obra do autor. É mantido pelo Karl Polanyi Institute of Political Economy, Concordia University, em Montreal, Canadá. Para mais informações, ver <https://www.concordia.ca/research/polanyi.html>.

5 Kari Polanyi-Levitt (I923- ) é professora emérita de economia na McGill University, Montreal, Canadá. Editora de importantes livros sobre a obra de Karl Polanyi (Aulenbacher et al., 2020; McRobbie \& Polanyi-Levitt, 2006; PolanyiLevitt, I990), seu trabalho mais conhecido se debruça sobre o tema do poder corporativo (Polanyi-Levitt, 2002).

6 A noção polanyiana de movimento duplo se refere às dinâmicas opostas e complementares de mercantilização, isto é, de ampliação do "controle mercantil sobre os meios de subsistência humanos", e da emergência de contramovimentos de proteção, sociais e políticos, em resposta à primeira. Segundo Dale (20I6b: 4), a relação entre esses movimentos foi interpretada de modo bastante diferente por seus seguidores e comentadores, sendo explorada em alguns dos trabalhos que integram o conjunto de textos desta edição da revista S\&A.

7 A noção de fetichismo da mercadoria é tratada extensamente na seção quarta ( $O$ caráter fetichista da mercadoria e o seu segredo) do capítulo primeiro (A mercadoria) do Livro I (O processo de produção do capital) de O Capital (Marx, 20I5).

8 Ao mobilizar a noção de economistic fallacy, o entrevistado se refere à tendência observada na ciência econômica mainstream (neoclássica e austríaca) a identificar a economia com sua forma de mercado e à "crença na existência de uma racionalidade econômica trans-histórica" (Dale, 20I6b: 34). A noção é discutida, de modo aprofundado, no ensaio "A falácia economicista", pelo próprio Polanyi (2012).

9 Influente sociólogo e economista político, assumiu a primeira cátedra dedicada à sociologia da Alemanha, na Universidade de Frankfurt. 
Io O Consórcio Norte Energia (Norte Energia S.A.) foi responsável pela construção da Usina Hidrelétrica (UHE) Belo Monte.

I I Economista e cientista político austríaco, célebre por sua análise do papel do empreendedor capitalista no processo de desenvolvimento econômico.

I2 A discussão entre oposição e progresso aparece no capítulo terceiro de A grande transformação (Polanyi, 20II).

\section{REFERÊNCIAS BIBLIOGRÁFICAS}

Aulenbacher, Brigitte et al. (eds.). (2020). Karl Polanyi: the life and works of an epochal thinker. Wien: Falter Verlag.

Birch, Kean, \& Muniesa, Fabian. (2020). Assetization: turning things into assets in technoscientific capitalism. Cambridge: MIT Press.

Block, Fred \& Somers, Margaret R. (2014). The power of market fundamentalism: Karl Polanyi's critique. Cambridge/ London: Harvard University Press.

Blyth, Mark. (2018). Austeridade: a história de uma ideia perigosa. São Paulo: Autonomia Literária.

Chiapello, Eve; Missemer, Antoine \& Pottier, Antonin. (2020). Faire l'économie de l'environnement. Paris: Presses des Mines.

Crouch, Colin. (20II). The strange non-death of neo-liberalism. Cambridge/Malden: Polity.

Dale, Gareth. (2016a). Karl Polanyi: a life on the left. New York: Columbia University Press.

Dale, Gareth. (20I6b). Reconstructing Karl Polanyi: excavation and critique. London: Pluto Press.

Dale, Gareth. (2010). Karl Polanyi: the limits of the market. Cambridge/Malden: Polity.

Dale, Gareth. (2007). The East German Revolution of 1989. Manchester: Manchester University Press.

Dale, Gareth; Mathai, Manu V. \& Oliveira, José A. P. de. (2016). Green growth: ideology, political economy and the alternatives. London: Zed Books. 
Foster, John Bellamy. (2005). A ecologia de Marx: materialismo e natureza. Rio de Janeiro: Civilização Brasileira.

Graeber, David. (2016). Dívida: os primeiros 5.000 anos. São Paulo: Três Estrelas.

Granovetter, Mark. (2007). Ação econômica e estrutura social: o problema da imersão. RAE eletrônica, 6/I, p. I-4I. Hann, Chris M. \& Hart, Keith (eds.). (2009). Market and society: The Great Transformation today. Cambridge/New York: Cambridge University Press.

Hillenkamp, Isabelle \& Laville, Jean-Louis (eds.). (20I6). Socioeconomia e democracia: a atualidade de Karl Polanyi. Porto Alegre: Escritos.

Marx, Karl. (20I5). O capital: crítica da economia política. Liuro I. O processo de produção do capital. São Paulo: Boitempo Editorial.

Mauss, Marcel. (2017). A nação. São Paulo: Três Estrelas.

McRobbie, Kenneth \& Polanyi-Levitt, Kari. (2006). Karl Polanyi in Vienna: the contemporary significante of The Great Transformation. 2 ed. Montreal: Black Rose Books.

Plehwe, Dieter; Slobodian, Quinn \& Mirowski, Philip (eds.). (2020). Nine lives of neoliberalism. London/New York: Verso Books.

Polanyi-Levitt, Kari (ed.). (2013). From The Great Transformation to the great financialization: on Karl Polanyi and other essays. London: Zed Books.

Polanyi-Levitt, Kari. (2002). Silent surrender: the multinational corporation in Canada. Toronto: McGill-Queen's University Press. (The Carleton Library Series, I96).

Polanyi-Levitt, Kari. (I990). Life and work of Karl Polanyi. Montreal: Black Rose Books.

Polanyi, Karl. (202I). A grande transformação: as origens da nossa época. Trad. C. Benjamin. Rio de Janeiro: Contraponto. Polanyi, Karl. (2014). For a new West: essays, I9I9-I958. Cambridge/Malden: Polity Press.

Polanyi, Karl. (20I2). A subsistência do homem e ensaios correlatos. Rio de Janeiro: Contraponto.

Polanyi, Karl. (20II). A grande transformação: as origens da nossa época. Trad F. Wrobel. São Paulo: Elsevier Brasil. 
Polanyi, Karl. (1977). The livelihood of man. New York/San Francisco/London: Academic Press.

Polanyi, Karl. (1966). Dahomey and the slave trade: an analysis of an archaic economy. Seattle: University of Washington Press.

Polanyi, Karl; Arensberg, Conrad M. \& Pearson, Harry W. (eds.). (1957). Trade and market in the early empires: economies in history and theory. Glencoe: The Free Press.

Sanchez-Sibony, Oscar. (20I4). Red globalization: the political economy of the Soviet cold war from Stalin to Khrushchev. Cambridge: Cambridge University Press.

Saito, Kohei. (20I7). Karl Marx's ecosocialism: capital, nature, and the unfinished critique of political economy. New York: New York University Press.

Snyder, Timothy. (2019). Na contramão da liberdade: a guinada autoritária nas democracias contemporâneas. São Paulo: Companhia das Letras.

Streeck, Wolfgang. (20I9). Tempo comprado: a crise adiada do capitalismo democrático. São Paulo: Boitempo Editorial. Vuillard, Éric. (20I9). A ordem do dia. Barcelona: Planeta. 


\section{CAPITALISMO, DEMOCRACIA E TEORIA SOCIAL EM KARL POLANYI: UMA ENTREVISTA COM GARETH DALE}

Resumo

Uma introdução à entrevista realizada com Gareth Dale (Brunel University) - economista político e especialista na trajetória e na obra de Karl Polanyi - e a um conjunto de textos inspirados na abordagem polanyiana publicados neste número de S\&A. Recupera questões-chave apresentadas na entrevista e na obra de Dale, dando relevo à literatura recente produzida sobre o autor, à contínua e difundida relevância das ideias de Polanyi para a compreensão do capitalismo e da democracia, e a uma leitura crítica e aberta de suas contribuições teóricas. Divulga as contribuições específicas, teóricas e empíricas, de quatro artigos originais que mobilizam ativamente conceitos polanyianos no entendimento da pluralidade dos processos de enraizamento e das dinâmicas do movimento duplo, de mercantilização da terra e do trabalho, e da centralidade da praça de mercado no capitalismo contemporâneo; além dos aportes de um registro de pesquisa e duas resenhas sobre agências e pedagogias econômicas e financeirização da vida cotidiana.

\section{CAPITALISM, DEMOCRACY, AND SOCIAL THEORY IN KARL POLANYI: AN INTERVIEW WITH GARETH DALE} Abstract

An introduction to the interview with Gareth Dale (Brunel University) - a political economist and expert on Karl Polanyi's life and work - and to a set of papers, inspired by the Polanyian approach, published in the current issue of S\&A. The paper highlights key questions presented in the interview and in Dale's work, with a focus on the recent literature produced about the author, the continuous and widespread relevance of Polanyi's ideas for the understanding of capitalism and democracy, and a critical and open reading of his theoretical contributions. Next, the paper presents the specific contributions, both theoretical and empirical, of four original papers that actively dip into Polanyian concepts in understanding the plurality of the embeddedness processes and the dynamics of the double movement, the commodification of land and labor, and the centrality of the marketplace in contemporary capitalism; as well as the contributions of a research recording and of two book reviews on economic agencies and pedagogies and the financialization of everyday life.
Palavras-chave

Karl Polanyi; Gareth Dale; capitalismo; democracia; mercado.

Keywords

Karl Polanyi; Gareth Dale; capitalism; democracy; market. 